\title{
Plasma alkaline phosphatase as a sensitive indicator of age and skeletal development in wild coscoroba swans
}

\author{
Cecilia P. Calabuig ${ }^{\text {A,C }}$, Miguel Ferrer ${ }^{\mathrm{A}}$, Roberto Muriel $^{\mathrm{A}}$ and Vallo Tilgar $^{\mathrm{B}}$ \\ ADepartment of Ethology and Biodiversity Conservation, Estación Biológica de Doñana, CSIC, \\ Avenida Americo Vespucio s/n, 41092 Sevilla, Spain. \\ BDepartment of Zoology, Institute of Ecology and Earth Sciences, University of Tartu, Vanemuise 46, \\ Tartu 51014, Estonia. \\ ${ }^{\mathrm{C}}$ Corresponding author. Email: cecicalabuig@ebd.csic.es
}

\begin{abstract}
Context. Recent studies have suggested that plasma alkaline phosphatase (ALP) can be used to assess skeletal development as well as health status in wild animals.

Aims. However, the information about age-related dynamics of ALP in birds, especially in precocial species, is very scarce. Therefore, before ALP measurements can be effectively interpreted, it is necessary to determine its normal variation for each species, age group and sex.

Methods. Here, we report total-ALP levels of free-living coscoroba swans (Coscoroba coscoroba) from the most important breeding and moulting population in Brazil. Data were gathered during the moulting period and categorised according to sex and the following three different age classes: chick $(n=11)$, young $(n=14)$ and mature $(n=29)$.

Key results. ALP levels were related to the longitudinal measure of the bones, gradually diminishing with age and showing significant differences among birds of different age classes. In all age groups, no effect of sex on T-ALP concentration was detected.

Conclusions. We conclude that measuring ALP facilitates the discrimination among different-aged individuals with similar plumage characteristics and body size.
\end{abstract}

\section{Introduction}

Reference blood-chemistry values for wild animals are of great importance. They facilitate the detection of possible pathological states as well as the evaluation of nutritional conditions, thus providing valuable biological data for ecological and behavioural studies (e.g. Ferrer 1990). However, before physiological measurements can be effectively interpreted and used in health assessment, it is necessary to understand their causes of variation.

Among blood parameters, the plasma alkaline phosphatase (ALP) is a potentially useful marker of growth and secondary ossification of the osseous tissue (e.g. Fleisch and Neuman 1961; Anderson 1976; Brown et al. 1983; Kan and Cress 1987; Viñuela and Ferrer 1997). There is still controversy about whether it acts in the proliferation of mesenchymal cells, expressing chondrogenic and osteogenic functions, or only in the deposition of calcium phosphate salts (e.g. Newbrey and Banks 1975; Warner et al. 1983; Salo et al. 1986). Recent studies have suggested that ALP may have useful applications for conservation measures (e.g. Dobado-Berrios and Ferrer 1997; Gambin et al. 1999; Kuz'mina et al. 2003; Grewal and Mahmood 2004; Tilgar et al. 2008a).

Total serum ALP (T-ALP) activity is the sum of ALP activities from different somatic compartments, namely bone, liver and intestine. In blood, the two most relevant isoforms of this enzyme are liver ALP and bone ALP (Romagnoli et al. 1998). The bone isoform (bone ALP) is a membrane-bound protein synthesised by osteoblasts in the bone tissue (de Behr et al. 2003) and it may be a sensitive indicator of skeletal development in both mammals (e.g. Takenaka et al. 1988; Price 1993; Hoffmann et al. 1999; Allen et al. 2000; de Behr et al. 2003) and birds (e.g. Viñuela et al. 1991; Cubo et al. 2000; Tilgar et al. 2004b, 2008a). For instance, Tilgar et al. (2008b) demonstrated that, in passerine birds, bone ALP was a better indicator of nestling maturity than traditionally used morphological measures. T-ALP activity has been associated with bone growth and age differences in various bird species, particularly in passerines, raptors and seabirds (e.g. Viñuela et al. 1991; Viñuela and Ferrer 1997; DobadoBerrios et al. 1998; Seiser et al. 2000; Villegas et al. 2002; Tilgar et al. 2004a). Further, a recent study with passerines indicated that T-ALP activity mostly reflects rapid mineralisation of long bones rather than delayed mineralisation of flat bones such as the skull (Tilgar et al. 2008a). However, no comparative studies are available for precocial birds.

Studies exploring ALP levels are common in developing young but scarce in full-grown individuals (e.g. Kirkwood et al. 1989; Dobado-Berrios and Ferrer 1997; Alonso-Alvarez 2005). At maturity, an increase in T-ALP has been related to the presence of toxins (Seiser et al. 2000, in pigeon quillemot, Cepphus columba), poor nutritional condition (Watkins et al. 2000, in rats, Rattus spp.) and the effects of captivity (Villegas 

et al. 2002, in black vulture, Aegypius monachus). ALP level is also known to increase in sick birds (Lewandowski et al. 1986). Overall, measuring reference values of ALP for each species and age group could provide valuable information on the physiological and pathological condition of several vertebrate groups. Determining ALP levels considering differentquality habitats, population trends or levels of anthropogenic disturbances is important; however, such information is currently very limited.

In Anatidae, few studies have related the levels of T-ALP to sex and/or age (Gee et al.1981, in Canada goose, Hawaiian goose, greater white-fronted goose and domestic goose; Driver 1981 and Fairbrother et al. 1990, in mallard; Boettcher 2004, in blacknecked swan). In the present paper, we investigated age- and sexrelated differences in the ALP level associated with morphology and skeletal growth in an endangered precocial bird, the coscoroba swan (Coscoroba coscoroba). In this species, T-ALP activity has been described during moulting (Calabuig et al. 2010a); however, reliable information about the variation in T-ALP related to skeletal development is still lacking for different age groups. We expect T-ALP activity in this species to be more reflective of the longitudinal growth of bones than that in altricial and semi-precocial birds (e.g. Tilgar et al. 2008a).

As a practical outcome, we questioned whether the measurement of plasma T-ALP in the coscoroba swan may facilitate the discrimination between sexually mature and immature individuals. First, in wild populations it is very difficult to detect visually plumage differences between the 2and 3-year-old birds, corresponding to young or sexually mature individuals, respectively. Therefore, little is known with certainty about their sexual maturation rates. For example, captive swans have been known to breed at 4 years of age, whereas the normal period for wild swans to attain sexual maturity may be of only 3 years (Johnsgard 1978; Silva-Garcia and Brewer 2007). Second, although mature birds tend to be bigger than young birds, on average, the range of most studied morphological measures overlaps among different age groups. Hence, it is very difficult to make a proper assessment of the individual age merely on the basis of morphological measurements. Additional indicators, such as T-ALP activity, may be very helpful. Previous studies on physiological, morphological and behavioural aspects of this species, either in wild or captive animals, have been merely descriptive or limited in scope regarding ALP measures (Nascimento et al. 2001; Seijas 2001; Menegheti and Dotto 2006; Silva-Garcia and Brewer 2007; Calabuig et al. 2010b).

Therefore, the main objectives of the present study were (i) to investigate the dynamics of T-ALP activity in the coscoroba swan in relation to age, sex and morphological parameters, and (ii) to determine the potential of T-ALP as an indicator of sexual maturity of birds with non-adult plumage (young versus mature).

\section{Materials and methods}

Coscoroba swans are found only in South America, from the Falkland Islands and Tierra del Fuego up to the north through Chile, Argentina, Uruguay and southern Brazil (Fjeldså and Krabbe 1990) reaching Paraguay. In Chile, it is reported to be endangered (Glade 1993). In Brazil, it is not mentioned in the list of threatened species but it has been described as an "insufficiently known' species and probably in danger of extinction (Bernardes et al. 1990; Nascimento et al. 2001).

\section{Capture}

We studied the coscoroba swan population of the national reserve of Taim Ecological Station $\left(32^{\circ} 33^{\circ} \mathrm{S}, 52^{\circ} 32^{\circ} \mathrm{W}\right)$, located in the southern coastal plain of Rio Grande do Sul State. This area covers the most important breeding and moulting sites for the coscoroba swan in Brazil (wet coastal areas) (Seijas 2001). The animals were captured in 2007, during moulting (between August and January), when they are not able to fly. The birds were caught manually from a boat (see Nascimento et al. 2001).

\section{Age identification and morphometrics}

The birds were classified in the following three age groups: chicks (birds of 6-27 days of age), young (fledged and no more than 2 years of age) and matures (more than 2 years old but still without adult plumage). The chick group consisted of 11 individuals, including four males, three females and four not sexed. The young group consisted of eight males and six females, a total of 14 individuals. The mature group consisted of 29 individuals, including 16 males and 13 females.

We used the plumage characteristics to distinguish among the age groups (Johnsgard 1978). Young, mature and adult coscoroba swans have red eyes, legs, feet and bill and there are age-specific differences in the plumage pattern. The adult's definitive plumage is totally white, with the exception of a black tip on the first six external primaries. Although their plumage is mainly white, young coscoroba swans have brownish down feathers and brightish-brown plumes all over the body and present greyishbrown stains on the tail, back and wings (in primaries, secondaries and upper wing coverts). Mature swans have grey down feathers only on the back and under the wings (axillaries). They usually present more than six primaries with greyish-brown flecks, whereas flecks occur very rarely on the secondaries.

Body mass was measured with Pesola spring balances (Pesola, Baar, Switzerland; for chick: T5 g; for young and mature: T25 g). We used a sliding calliper (E-Base Measuring Tools Co., Pao-Chung Yun-Lin, Taiwan; T0.1 mm) for measurement of linear morphometrics, including total length of the head (TLH, Fig. 1) from the occipital to the tip of the bill, height of the bill (HBI, Fig. 1), width of the bill (WBI, Mathiasson 1980), nostril (Fig. 1), total culmen (TCU, Fig. 1) and tarsus length (Bourgeois et al. 2007). Tail (Albertsen et al. 2002), featherless wing (metacarpophalangeal articulation, Fig. 2), forearm (Fig. 2) and length of the neck (LN) (Mathiasson 2005) measurements were taken with a ruler marked in millimetres (E-Base Measuring Tools Co.; T0.1 mm). Depending on the size of the chick, we did not measure all morphometric parameters either because of the difficulty to do so (e.g. the length of the neck) or the unclear development stage (forearm and tail). To avoid observer bias, only one technician was responsible for collecting morphometrical data and for determining sex.

Before release, all animals were marked with numbered metallic rings around the tarsus at the Center of National Research for Conservation of Wild Birds - Brazilian Institute 


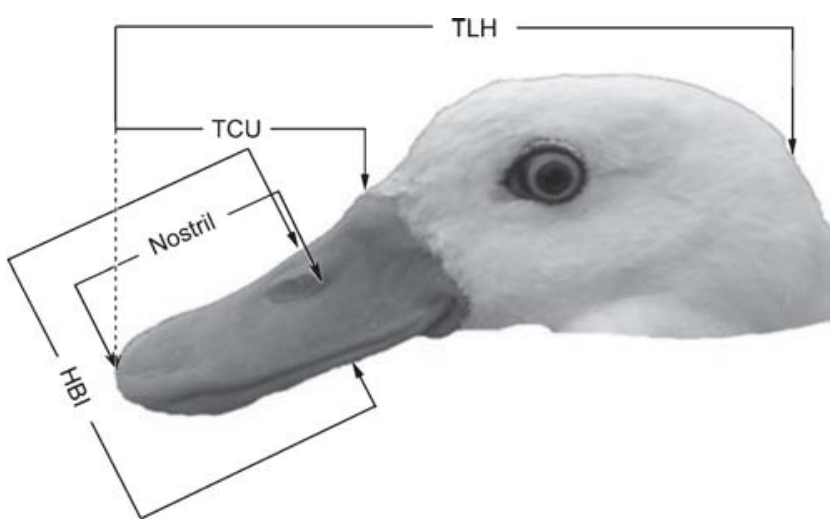

Fig. 1. Lateral view of the head of a coscoroba swan, showing the head measurements of total length of head (TLH); total length of culmen (TCU); nostrial and height of bill (HBI). (Photograph: Cecilia Calabuig.)

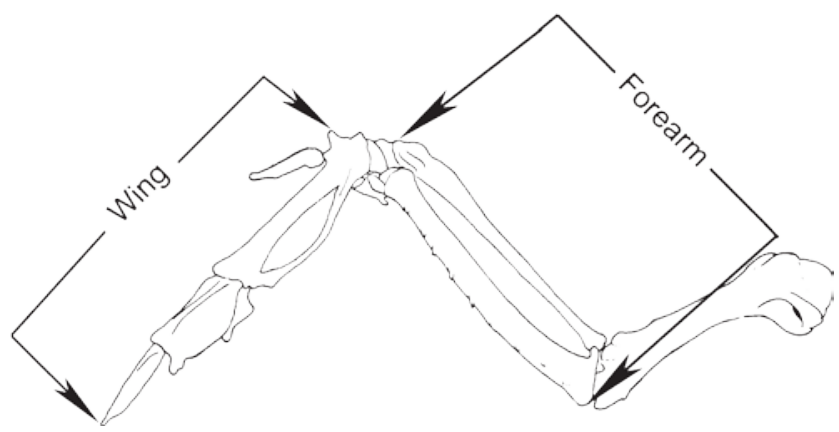

Fig. 2. The skeletal structure of the wing of the coscoroba swan, showing forearm and wing measurements.

of Environment and Renewable Natural Resources (CEMAVEIBAMA) for individual identification, as well as for survival and displacement studies.

\section{Blood sampling}

A blood sample (100-500 mL) was collected from the radial vein between 1100 hours and 1400 hours so as to minimise variation caused by circadian rhythms (Ferrer 1990). Samples were placed in tubes containing lithium heparin and kept cool $\left(4^{\circ} \mathrm{C}\right)$ for a maximum of $5 \mathrm{~h}$. Then, they were centrifuged (10 000g for $10 \mathrm{~min}$ ) to extract the plasma by using Eppendorf Centrifuge 5415 (Eppendorf, Hamburg). Subsequent analyses were performed with a portable autoanalyser (Reflotron II; F. Hoffmann-La Roche, Basel, Switzerland), with the reagent recommended by Roche Diagnostic at $30^{\circ} \mathrm{C}$ in $\mathrm{UL}^{-1}$ (ALP, method recommended by International Federation of Oinical Chemistry (IFCC) liquid method) (Solberg 1987).

For sex identification, blood samples were stored in vacutainer tubes with EDTA and kept cool on ice, until processing. In the case of chicks, we sometimes failed to collect sufficient amount of blood for simultaneous analysis of sex and T-ALP.

\section{Sex determination}

The following two methods of sex identification were used: genital identification for mature birds (males present an erectile groove penis on the ventral wall of the cloacae,
Proctor and Lynch 1993) and DNA identification for young birds and chicks. DNA extraction was performed according to previously described procedures (Lahiri and Nurnberger 1991). After the extraction, we used the method described by He et al. (2005) for the black swan (Cygnus atratus). The samples were analysed in the Biotechnology Center (CenBiot) of the Federal University of Pelotas (Brazil).

Blood-sample collection was carried out under the Licence No. 10209-1, issued by Biodiversity Authorisation and Information System - Brazilian Institute of Environment and Renewable Natural Resources (SISBIO-IBAMA). All analyses were approved by and performed according to the guidelines of the Ethics Committee on Animal Experimentation from Federal University of Pelotas.

\section{Statistical analysis}

The statistical analyses were performed in Statistica 7.0 (StatSoft, Tulsa, OK) and we considered an a level of 0.05. We checked normality and homoscedasticity by Lilliefors and Levene tests, respectively. Dependent variables were log10-transformed to attain normality.

Morphometric differences according to sex and age

We used a two-way ANOVA with Type III error, considering age and sex as fixed factors and each morphometric parameter (TLH, HBI, WBI, nostril, TCU, tarsus, tail, wing, forearm and LN) as an dependent variable. We used Tukey's HSD test for pairwise comparisons between sexes and different age groups.

T-ALP according to age and sex

We analysed the differences in the mean concentration of plasma T-ALP (log10ALP) among the age groups, sexes and their interactions, using an ANOVA with Type III error term. We used Tukey's HSD test for pairwise comparisons between sexes and age groups.

T-ALP according to morphometric measures and age

Using T-ALP (log10ALP) as the dependent variable, we conducted a simple regression for each morphometric parameter (TLH, HBI, WBI, nostril, TCU, tarsus, tail, wing, forearm and LN) (i) for each age group separately and (ii) across age groups, but without correcting for age effects. Additionaly, we conducted a simple regression for chicks, by using age (in days) as an independent variable. Tail, forearm and length of the neck were excluded from the morphometric analysis of this group because of a small sample size $(n=6)$.

Then, with T-ALP (log10ALP) as the dependent variable, we also conducted a multiple-regression analysis considering age (chicks, young and mature birds), each morphometric parameter (WBI, HBI and wing) and weight as independent variables in the same model.

Standardised $b$ values (b) were obtained from each model to represent the partial correlation between the dependent variable and the predictors.

\section{Results}

Morphometric differences according to sex and age

Analysis showed that most of the morphometric parameters differed significantly among the age groups (d.f.=3, 43; 
$\mathrm{F}=3.2 ; \mathrm{P}<0.01$, Table 1) but not between the sexes (d.f. = 3, 43; $\mathrm{F}=2 ; \mathrm{P}=0.06$, Table 1).

\section{T-ALP in relation to age and sex}

The T-ALP concentration showed a clear decrease with age (d.f. $=2,46 ; \mathrm{F}=68.7 ; \mathrm{b}=-0.5, \mathrm{P}<0.01$ ). In this sense, T-ALP levels were significant higher in chicks than in young and mature birds (Tukey's HSD test: $\mathrm{P}<0.01$ ) and also significantly higher in young than in mature (Tukey's HSD test: $\mathrm{P}=0.03$ ) (Fig. 3). No significant differences in T-ALP concentration were found between males and females (d.f. = 1,46; F = 3.1; Tukey's HSD test: $\mathrm{P}>0.05)$ and also in the interaction between sex and age (d.f. $=2,44 ; \mathrm{F}=0.1 ; \mathrm{P}>0.05$ ).

\section{T-ALP in relation to morphometric measures and age}

In mature and young birds, none of the morphometric variables was correlated with T-ALP (mature birds: d.f. $=1,12$, P > 0.05; young birds: d.f. $=1,27, \mathrm{P}>0.05)$. Whereas chicks showed a highly significant negative relationship with T-ALP for all bone measures (TCU-F $=12.2$; nostril-F $=11.4$; $\mathrm{HBI}-\mathrm{F}=13$; $\mathrm{WBI}-\mathrm{F}=12.8$; $\mathrm{THL}-\mathrm{F}=13.6$; tarsus-F = 13.1; weight-F = 10.7; d.f. $=1,9, \mathrm{~b}>-0.7$ and $\mathrm{P}<0.01$ for all measures) except the wing length $(\mathrm{P}>0.05)$. Moreover, the relationship between the T-ALP concentration and chick age measured in days was significant (age in days: d.f. $=1,9 ; \mathrm{F}=11.5 ; \mathrm{P}<0.01, \mathrm{~b}=-0.75$; Fig. 4).

Across the age groups, without including age effects, the relationship between morphometric parameters and T-ALP concentration was highly significant for all bone measurements and weight, except for the LN and tail length (Table 2).

The multiple-regression model with the most relevant morphometric variables (WBI, HBI, wing and weight, F Ç72.8 and $\mathrm{b}$ Ç-0.77) and age class (chick, young and mature) retained only age class as a significant predictor (d.f. $=5.47$; $\mathrm{F}=34.9$; $\mathrm{P}<0.01, \mathrm{~b}=-0.64$; Fig. 3). Note that the interaction between age and each of these morphometric parameters was not significant in any model and was therefore excluded from all final models.

\section{Discussion}

We found that T-ALP activity reflected age differences between young and mature individuals. Furthermore, T-ALP analysis was unable to determine sex in similar-aged birds. Thus, T-ALP measurements might help researchers to discriminate between different age groups in species where age is difficult to assess by using morphological or plumage characteristics. Unlike in altricial birds, we demonstrated that the T-ALP concentration of this precocial species was significantly and inversely related to the elongation of long bones.

\section{T-ALP in relation to age and sex}

Our results showed consistent age-related differences in T-ALP levels. Plasmatic concentrations of this enzyme gradually decreased from chicks (1077.8 $\left.\mathrm{T} 585.6 \mathrm{U} \mathrm{L}^{-1}\right)$ to young

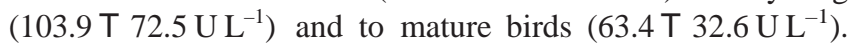
These results are in agreement with those of other studies on Anatidae (Gee et al. 1981; Olsen et al. 2002; Boettcher 2004) and raptors (e.g. Viñuela et al. 1991; Puerta et al. 1992; DobadoBerrios and Ferrer 1997). Highly elevated levels of ALP in chicks of the coscoroba swan can be associated with calcium deposition in the skeleton, as a function of intensive bone ossification and elongation during the rapid growth phase (Tilgar et al. 2008a). In 1-year-old young and 2- and 3-year-old mature birds, whose skeletal growth is almost completed and mineralisation is predominantly related to appositional bone growth, the ALP level is remarkably lower than that in chicks (see e.g. Mathiasson 1980, 2005; Miller et al. 1988; Whitehead and Tschirner 1990; Badzinski et al. 2002). We found that the final stabilisation of ALP at a minimum level occurs in mature birds and it is probably associated with the completion of skeletal mineralisation and the achievement of the final structural size. Similar results in mature birds have also been reported in other studies of Anatidae (e.g. Perry et al.1986; Polo 1995; Olayemi et al. 2002). However, further research in different age groups of precocial species is needed to measure the rate of bone mineralisation in parallel with ALP dynamics.

Unlike in other studies of Anatidae (Gee et al. 1981; Polo 1995), no sexual differences in the T-ALP concentration were observed in the coscoroba swan in the present study. Hence, we suggest that species-specific differences may occur even among precocial species. Additional studies are needed to confirm the generality of this finding.

\section{T-ALP, morphometric measures and age}

Our study showed that none of the morphometric parameters of chicks, young and mature swans was correlated with the T-ALP concentration when the age effects were considered. Age effects may mask relationships between the morphometric parameters and T-ALP concentration because all parameters inserted as predictors into the models were tightly related to age. Moreover, a serious collinearity problem can emerge when predictors are inter-related to each other, thus reducing the reliability of such models.

However, without correcting for age effects, T-ALP was inversely related to all skeletal parameters. The question remains whether the decline in ALP values with increasing body size is more reflective of the completion of skeletal growth (bone elongation) or due to the reduction in the rate of skeletal mineralisation. Tilgar et al. (2008a) showed that the T-ALP concentration measured throughout the nestling period reflects the overall rate of skeletal mineralisation in the great tit (Parus major). However, they found no evidence that the elongation of long bones is correlated with the T-ALP concentration. According to Carrier and Auriemma (1992), skeletal development must be faster in altricial than in precocial birds. Kirkwood et al. (1989) showed that tarsometatarsal growth rate is, on average, three times greater in altricial hatchlings (those that do not leave the nest immediately after hatching) than in precocial hatchlings (those that run actively) of similar adult weight. Unlike precocial birds (our study), altricial passerines or semi-precocial raptors (e.g. Dobado-Berrios and Ferrer 1997; Dutta et al. 1998; Ferrer and Dobado-Berrios 1998; Mänd et al. 2000; Tilgar et al. 2008a) attain full skeletal size several days before fledging. Hence, in the latter species, differences in the amount of skeletal calcium between fledglings and mature birds may be attributed mainly to incomplete skeletal mineralisation and not to bone elongation. To confirm/clarify this pattern in precocial 
Table 1. Descriptive morphometric measures (mean \pm s.d., in mm) for total culmen (TCU), nostril, height of the bill (HBI), width of the bill (WBI), length of the head (TLH), tarsus length, wing, forearm, tail and length of neck (LN) for the three age groups studied (chicks, young, mature) of coscoroba swan

Tukey's HSD post hoc test considered age and sex as fixed factors and the morphometric measures as dependent variables. n, sample size; P-values are given for differences between chicks and young $(\mathrm{C} \times \mathrm{Y})$, young and mature $(\mathrm{Y} \times \mathrm{M})$ and male and female $(\mathrm{M} \times \mathrm{F})$. For the Tukey HSD test between chicks and mature, $\mathrm{P}<0.01$ for all measures, except for tarsus $\mathrm{P}=0.01$

\begin{tabular}{|c|c|c|c|c|c|c|c|c|c|c|c|c|c|c|c|}
\hline \multirow[t]{3}{*}{ Measure } & \multicolumn{10}{|c|}{ Age group } & \multicolumn{5}{|c|}{ Sex } \\
\hline & & Total & & Chicks & & Young & & Mature & $\mathrm{C} \times \mathrm{Y}$ & $\mathrm{Y} \times \mathrm{M}$ & & Male & & Female & $\mathrm{M} \times \mathrm{F}$ \\
\hline & $\mathrm{n}$ & Mean \pm s.d. & $\mathrm{n}$ & Mean \pm s.d. & $\mathrm{n}$ & Mean \pm s.d. & $\mathrm{n}$ & Mean \pm s.d. & $\mathrm{P}$ & $\mathrm{P}$ & $\mathrm{n}$ & Mean \pm s.d. & $\mathrm{n}$ & Mean \pm s.d. & $\mathrm{P}$ \\
\hline TCU & 43 & $62.9 \pm 14.5$ & 4 & $41.2 \pm 19.8$ & 14 & $67.2 \pm 2.9$ & 25 & $69.1 \pm 4.4$ & $<0.01$ & $>0.05$ & 23 & $65.4 \pm 12.5$ & 20 & $64.6 \pm 10.6$ & 0.01 \\
\hline Nostril & 43 & $47.9 \pm 11.4$ & 4 & $31 \pm 15.3$ & 14 & $50.4 \pm 3.9$ & 25 & $53.1 \pm 3.8$ & 0.04 & $>0.05$ & 23 & $49.9 \pm 10.6$ & 20 & $49.2 \pm 7.8$ & 0.02 \\
\hline HBI & 43 & $23.6 \pm 4.4$ & 4 & $17 \pm 6.1$ & 14 & $24.5 \pm 1$ & 25 & $25.6 \pm 1.4$ & 0.02 & 0.01 & 23 & $24.7 \pm 3.9$ & 20 & $23.7 \pm 3$ & $<0.01$ \\
\hline WBI & 43 & $27.7 \pm 5.4$ & 4 & $19.5 \pm 7.4$ & 14 & $29.4 \pm 1.6$ & 25 & $29.9 \pm 1.1$ & $<0.01$ & $>0.05$ & 23 & $28.7 \pm 4.8$ & 20 & $28.2 \pm 3.7$ & 0.01 \\
\hline THL & 43 & $125.7 \pm 25$ & 4 & $88.3 \pm 35.1$ & 14 & $132 \pm 5.7$ & 25 & $136.7 \pm 5.5$ & $<0.01$ & 0.03 & 23 & $130.7 \pm 22.2$ & 20 & $128.2 \pm 17.3$ & $<0.01$ \\
\hline Tarsus & 43 & $92.5 \pm 21.6$ & 4 & $62 \pm 31.5$ & 14 & $97.7 \pm 7.1$ & 25 & $101.8 \pm 5.1$ & $>0.05$ & $>0.05$ & 23 & $96.7 \pm 19$ & 20 & $94.7 \pm 14.3$ & 0.01 \\
\hline Wing & 43 & $158.1 \pm 41.9$ & 4 & $88.6 \pm 50.8$ & 14 & $168 \pm 10.6$ & 25 & $178.2 \pm 12$ & $<0.01$ & $>0.05$ & 23 & $166.6 \pm 35.2$ & 20 & $163 \pm 28.9$ & $<0.01$ \\
\hline Forearm & 48 & $203 \pm 18.2$ & 5 & $163 \pm 37.3$ & 14 & $206 \pm 11.9$ & 25 & $207 \pm 9.1$ & $<0.01$ & $>0.05$ & 25 & $209.5 \pm 10.4$ & 22 & $195.2 \pm 22.2$ & $<0.01$ \\
\hline Tail & 48 & $182 \pm 20.9$ & 5 & $139 \pm 26.7$ & 14 & $189 \pm 17.7$ & 25 & $184.9 \pm 13.9$ & $<0.01$ & $>0.05$ & 25 & $186.5 \pm 12.9$ & 22 & $176.7 \pm 27.5$ & 0.04 \\
\hline LN & 48 & $327 \pm 33.4$ & 5 & $290 \pm 26.1$ & 14 & $323 \pm 40$ & 25 & $334.9 \pm 27.9$ & $>0.05$ & $>0.05$ & 25 & $339.7 \pm 24.4$ & 22 & $313.9 \pm 37.9$ & $<0.01$ \\
\hline
\end{tabular}




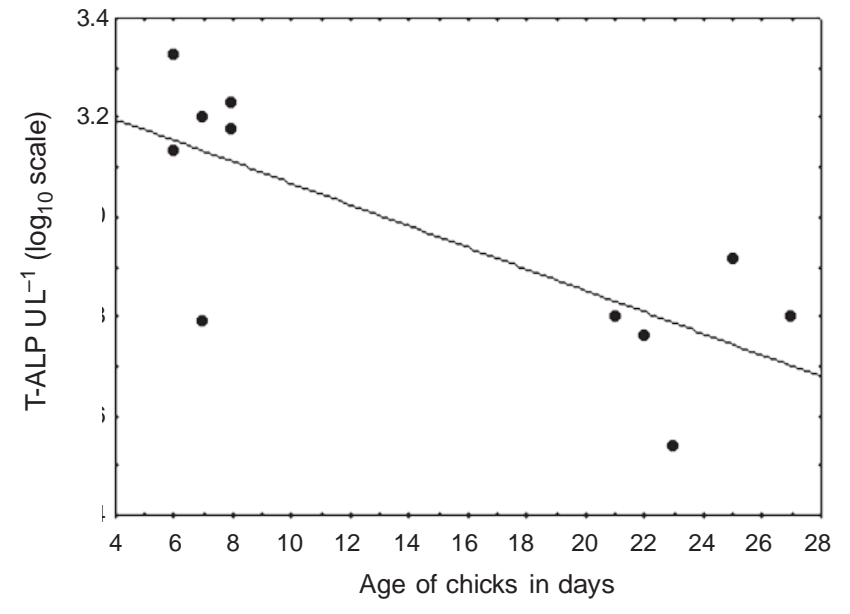

Fig. 3. Mean (mean T 1 s.e.) plasma alkaline phosphatase in relation to age of coscoroba swans. $\mathrm{n}=$ sample size in each age class.

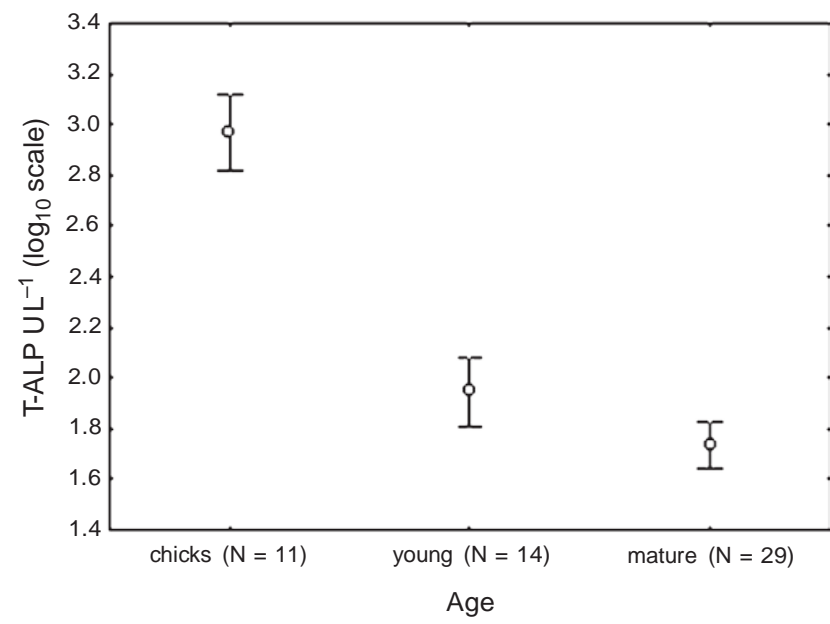

Fig. 4. Age-related variation in plasma levels of alkaline phosphatase of coscoroba chicks.

species, future studies should focus on measuring the skeletal calcium concentrations in different age groups. We believe that there is a need for comparative studies demonstrating the role of ALP in species with different life histories.

\section{Applications of T-ALP in population ecology}

A proper assessment of the population age structure of both reproducing and non-reproducing individuals is of great importance for conservation and management purposes. In the coscoroba swan, the discrimination of young and mature birds is very complicated in wild populations because of their similar size and plumage characteristics. For example, during our fieldwork we found that coscoroba swans with adult plumage represented only $9.6 \%$ of the full-grown individuals of the population (Calabuig et al. 2010b). Silva-Garcia and Brewer (2007) also found that in central Chile, at least $70 \%$ of the population were young swans.
Table 2. Results from simple regressions between the T-ALP concentration for all birds pooled together of coscoroba swan, without including age effects, and the morphometric measures n, sample size; TCU, total culmen; HBI, height of the bill; WBI, width of the bill; TLH, length of the head; LN, length of neck

\begin{tabular}{lcrccc}
\hline Measure & $\mathrm{n}$ & $\mathrm{F}$ & d.f. & $\mathrm{b}$ & $\mathrm{P}$ \\
\hline TCU & 54 & 68.7 & 1,52 & -0.75 & $<0.01$ \\
Nostril & 54 & 55.3 & 1,52 & -0.72 & $<0.01$ \\
HBI & 54 & 78 & 1,52 & -0.77 & $<0.01$ \\
WBI & 54 & 82.9 & 1,52 & -0.78 & $<0.01$ \\
THL & 54 & 70.8 & 1,52 & -0.76 & $<0.01$ \\
Tarsus & 54 & 70.1 & 1,52 & -0.76 & $<0.01$ \\
Wing & 54 & 72.8 & 1,52 & -0.77 & $<0.01$ \\
Forearm & 48 & 5.1 & 1,46 & -0.32 & 0.03 \\
Tail & 48 & 3.1 & 1,46 & -0.25 & $>0.05$ \\
LN & 48 & 2.8 & 1,46 & -0.24 & $>0.05$ \\
Weight & 54 & 73.9 & 1,52 & -0.77 & $<0.01$ \\
\hline
\end{tabular}

Hence, to identify the age correctly, T-ALP can be used as a complementary tool for age assessment. It is also a reliable indicator of sexual maturity. Normal plasma ALP levels have very small overlap ranges between young and mature birds, the latter having a remarkably lower level of ALP than the former. We emphasise that a complex approach, which includes ALP measure and the determination of plumage characteristics and body size, would provide the most reliable estimate of age. However, to verify the suitability of this method, further studies with different populations are necessary.

T-ALP can be used as an additional tool (e.g. to ringing and recapture data) for the correct determination of the age of individuals. Therefore, the measurement of ALP in birds can also facilitate studies between different populations. Establishing a normal range of serum ALP levels for different age groups would allow us to detect potential abnormalities in bone formation or in health status (see Introduction). Assuming that our population of coscoroba swan represents a healthy population (see Calabuig et al. 2010a for the normal values of 10 biochemical parameters in this population), these values would provide normal ranges of ALP concentration that could be used for comparisons among populations of this species. If ALP values for a given population and age group are significantly elevated in comparison with the reference population, this might indicate negative pressures on the population, e.g. individuals suffering health problems as a result of environmental pollution (increased exposure to toxins), infections, diseases and food deficiency. Hence, the information from the present study would serve as a basis for future researchers monitoring the health status of wild coscoroba swan populations. It may also be useful for future treatment of captive coscoroba swans in zoological parks or in rehabilitation situations. In conclusion, we suggest that variation in the plasma ALP certainly deserves more attention from avian ecologists and conservation biologists than it has received in the past.

\section{Acknowledgements}

We thank S. Scherer for the valuable assistance in the field. Thanks go to Dr H. Moreira, Dr B. Vaz and J. Camacho from Department of Genetics 
and Zoology, Federal University of Pelotas, RS, Brazil, for carrying out the molecular sexing of non-mature coscoroba swans, to M. Katzenberger for very useful comments on the manuscript, and to an anonymous referee for the comments that substantially improved the paper.

\section{References}

Albertsen, J. O., Abe, Y., Kashikawa, S., Ookawara, A., and Tamada, K. (2002). Age and sex differences in biometrics data recorded for whooper swans wintering in Japan. Waterbirds 25, 334-339.

Allen, L. C. V., Allen, M. J., Breur, G. J., Hoffmann, W. E., and Richardson, D. C. (2000). A comparison of two techniques for the determination of serum bone-specific alkaline phosphatase activity in dogs. Research in Veterinary Science 68, 231-235. doi:10.1053/rvsc.1999.0369

Alonso-Alvarez, C. (2005). Age-dependent changes in plasma biochemistry of yellow-legged gulls (Larus cachinnans). Comparative Biochemistry and Physiology. A. Comparative Physiology 140, 512-518.

Anderson, H. C. (1976). Matrix vesicles of cartilage and bone. In 'The biochemistry and physiology of bone'. (Ed. G. H. Bourne.) pp. 135-157. (Academic Press: New York.)

Badzinski, S. S., Ankney, C. D., Leafloor, J. O., and Abraham, K. F. (2002). Growth and development of Canada geese and lesser snow geese: ecological adaptation or physiological constraint? The Auk 119, 221-227. doi:10.1642/0004-8038(2002)119[0221:GADOPC]2.0.CO;2

Bernardes, A. T., Machado, A. B. M., and Rylands, A. B. (1990). 'Fauna Brasileira Ameacada de Extincao.' (Fundação Biodiversitas, Belo Horizonte: Minas Gerais, Brazil.)

Boettcher, A. A. (2004). Valores bioquímicos sanguíneos del cisne de cuello negro (Cygnus melanocoryphus, Molina 1782), en una población silvestre de Valdivia, Chile. Degree Dissertation, University Austral de Chile, Valdivia, Chile.

Bourgeois, K., Curé, C., Legrand, J., Gómez-Díaz, E., Vidal, E., Aubin, T., and Mathevon, N. (2007). Morphological versus acoustic analysis: what is the most efficient method for sexing yelkouan shearwaters Puffinus yelkouan? Journal fur Ornithologie 148, 261-269. doi:10.1007/s10336007-0127-3

Brown, R. D., Chao, C. C., and Faulkner, L. W. (1983). Hormone levels and antler development in white-tailed and sika fawns. Comparative Biochemistry and Physiology 75, 385-390. doi:10.1016/0300-9629(83) 90098-1

Calabuig, P. C., Ferrer, M., and Muriel, R. (2010a). Blood chemistry of wild Brazilian coscoroba swans during molt. Journal of Wildlife Diseases 46, 591-595.

Calabuig, P. C., Green, J. A., Muriel, R., and Patino, J. (2010b). Fenología del coscoroba (Coscoroba coscoroba) en el sur de Brasil y sus movimientos hacia Argentina. Ornitología Neotropical, in press.

Carrier, D. R., and Auriemma, J. (1992). A developmental constraint on the fledging time of birds. Biological Journal of the Linnean Society. Linnean Society of London 47, 61-77. doi:10.1111/j.1095-8312.1992. tb00656.x

Cubo, J., Fouces, V., Gonzales-Martin, M., Pedrocchi, V., and Ruiz, X. (2000). Nonheterochronic developmental changes underlie morphological heterochrony in the evolution of the Ardeidae. Journal of Evolutionary Biology 13, 269-276. doi:10.1046/j.1420-9101.2000. 00163.x

de Behr, V., Daron, D., Gabriel, A., Remy, B., Dufrasne, I., Serteyn, D., and Istasse, L. (2003). The course of some bone remodelling plasma metabolites in healthy horses and in horses offered a calcium-deficient diet. Journal of Animal Physiology and Animal Nutrition 87, 149-159.

Dobado-Berrios, P., and Ferrer, M. (1997). Age-related changes of plasma alkaline phosphatase and inorganic phosphorus, and late ossification of the cranial roof in the Spanish imperial eagle (Aquila adalberti). Physiological Zoology 70, 421-427. doi:10.1086/515845
Dobado-Berrios, P., Tella, J. L., Ceballos, O., and Donazar, J. A. (1998). Effect of age and captivity on plasma chemistry values of the Egyptian vulture. The Condor 100, 719-725. doi:10.2307/1369754

Driver, E. A. (1981). Hematological and blood chemical values of mallard, Anas p. platyrhynchos, drakes before, during and right after remige moult. Journal of Wildlife Diseases 17, 413-421.

Dutta, C., Johnson, L. S., Larkin, D., and Mangurian, L. P. (1998). Skeletal development at the time of fledging in house wrens. The Condor 100, 568-573. doi:10.2307/1369728

Fairbrother, A., Craig, M. A., Walker, K., and O’Loughlin, D. (1990). Changes in mallard (Anas platyrhynchos) serum chemistry due to age, sex, and reproductive condition. Journal of Wildlife Diseases 26, $66-67$.

Ferrer, M. (1990). Haematological studies in birds. The Condor 92, 1085-1086. doi:10.2307/1368750

Ferrer, M., and Dobado-Berrios, P. (1998). Factors affecting plasma chemistry values of the Spanish imperial eagle, Aquila adalberti. Comparative Biochemistry and Physiology. A. Comparative Physiology 120, 209-217.

Fjeldså, J., and Krabbe, N. (1990). 'Birds of the High Andes.' (Zoological Museum, University of Copenhagen, and Apolo Books: Svendurg, Denmark.)

Fleisch, H., and Neuman, W. F. (1961). Mechanisms of calcification: role of collagen, polyphosphates, and phosphatase. American Journal of Physiology 200, 1296-1300.

Gambin, F., Bogé, G., and Jamet, D. (1999). Alkaline phosphatase in a littoral Mediterranean marine ecosystem: role of the main plankton size classes. Marine Environmental Research 47, 441-456. doi:10.1016/ S0141-1136(98)00130-5

Gee, G. F., Carpenter, J. W., and Hensler, G. L. (1981). Species differences in haematological values of captive cranes, geese, raptors and quail. The Journal of Wildlife Management 45, 463-483. doi:10.2307/3807928

Glade, A. A. (1993). 'Libro Rojo de los Vertebrados Terrestres de Chile.' (Corporación Nacional Forestal (CONAF): Santiago de Chile.)

Grewal, R., and Mahmood, A. (2004). Coordinated secretion of alkaline phosphatase into serum and intestine in fat-fed rats. Indian Journal of Gastroenterology 23, 175-177.

He, P.-J., Yu, J.-Q., and Fang, S.-G. (2005). Sex identification of black swan (Cygnus atratus) using the locus/specific and implications for this reproduction. Reproduction in Domestic Animals 40, 196-198. doi:10.1111/j.1439-0531.2005.00562.x

Hoffmann, W. E., Solter, P. F., and Wilson, B. W. (1999). Clinical enzymology. In 'The Clinical Chemistry of Laboratory Animals'. (Eds W. F. Loeb and F. W. Quimby.) pp. 399-454. (Taylor and Francis: Philadelphia, PA.)

Johnsgard, P. (1978). ‘Ducks, Geese, and Swans of the World.' (University of Nebraska Press: Lincoln, NE.)

Kan, K. W., and Cress, R. L. (1987). Temporal relationship between fetal bovine skeletal growth and circulating hormone levels. Calcified Tissue International 40, 137-148. doi:10.1007/BF02555698

Kirkwood, J. K., Duignan, P. J., Kember, N. F., Bennett, P. M., and Price, D. J. (1989). The growth rate of the tarsometatarsus bone in birds. Journal of Zoology 217, 403-416. doi:10.1111/j.1469-7998.1989.tb02498.x

Kuz'mina, V., Glatman, L., Drabkin, V., and Gelman, A. (2003). Amylolytic activity in fish intestinal mucosa: temperature effects. Comparative Biochemistry and Physiology. B, Comparative Biochemistry 134, 529-534. doi:10.1016/S1096-4959(03)00005-8

Lahiri, D. K., and Nurnberger, J. I., Jr (1991). A rapid non-enzymatic method for the preparation of HMW DNA from blood for RFLP studies. Nucleic Acids Research 19, 5444. doi:10.1093/nar/19.19.5444

Lewandowski, A. H., Campbell, T. W., and Harrison, G. J. (1986). Clinical chemistries. In 'Clinical Avian Medicine and Surgery'. (Eds G. H. Harrison and L. R. Harrison.) pp. 192-200. (Saunders: Philadelphia, PA.) 
Mänd, R., Tilgar, V., and Leivits, A. (2000). Reproductive response of great tits, Parus major, in a naturally base-poor forest habitat to calcium supplementation. Canadian Journal of Zoology 78, 689-695. doi:10.1139/cjz-78-5-689

Mathiasson, S. (1980). Weight and growth rates of morphological characters of Cygnus olor. In 'Proceedings, 2nd International Swan Symposium'. (Eds G. V. T. Matthews and M. Smart.) pp. 379-389. (IWRB: Sapporo, Japan.)

Mathiasson, S. (2005). Biometrics and structures of the mute swan, Cygnus olor - parameters and technique used in a Swedish project. Göteborgs Naturhistoriska Museum Årstryck 2005, 77-86.

Menegheti, J. O., and Dotto, J. C. (2006). Status of the black-necked swan Cygnus melanocorypha and coscoroba swan Coscoroba coscoroba in the south of Brazil. In 'Waterbirds around the World'. (Eds G. C. Boere and D. A. Stroud.) pp. 183-184. (The Stationery Office: Edinburgh, UK.)

Miller, S. L., Gregg, M. A., Kuritsubo, A. R., Combs, S. M., Murdock, M. K., Nilsson, J. A., Noon, B. R., and Botzler, R. G. (1988). Morphometric variation in tundra swans: relationships among sex and age classes. The Condor 90, 802-815. doi:10.2307/1368837

Nascimento, J. L. X., Flores, J. M., Ataguile, B. S., Koch, M., Barbosa, S., and Parreira dos Santos, P. J. (2001). Biological aspects of the black-necked swan (Cygnus melancoryphus) and coscoroba swan (Coscoroba coscoroba) in Rio Grande do Sul state, Brazil. Melopsittacus 4, 31-38.

Newbrey, J. W., and Banks, W. J. (1975). Characterization of developing antler cartilage matrix. 11. An ultrastructural study. Calcified Tissue Research 17, 289-302. doi:10.1007/BF02546601

Olayemi, F. O., Arowolo, R. O. A., Saba, A. B., and Famakinde, S. A. (2002). Effect of sex on the blood profiles of the Nigerian local duck. Bulletin of Animal Health and Production in Africa 50, 67-71.

Olsen, G., Rininger, D., Ets, M., and Sladen, W. (2002). Baseline haematology and clinical chemistry results from captive-raised trumpeter swans. Waterbirds 25(Special Publication 1), 375-379.

Perry, M., Obrecht, H., Williams, B., and Kuenzel, W. (1986). Blood chemistry and hematocrit of captive and wild canvasbacks. The Journal of Wildlife Management 50, 435-441. doi:10.2307/3801100

Polo, F. J. (1995). Estudio bioquımico y enzimatico del plasma de aves en cautividad. Ph.D. Thesis. Universidad de Barcelona, Spain.

Price, C. P. (1993). Multiple forms of human serum alkaline phosphatase: detection and quantification. Annals of Clinical Biochemistry 30, 355-372.

Proctor, N. S., and Lynch, P. J. (1993). 'Manual of Ornithology: Avian

Structure and Function.' (Yale University Press: New Haven, CT.) Puerta, M. L., Garcia del Campo, A. L., Abendela, M., Fernandez, A., Huecas, V., and Nava, M. P. (1992). Hematological trends in flamingos, Phoenicopterus tuber. Comparative Biochemistry and Physiology. A. Comparative Physiology 102, 683-686. doi:10.1016/0300-9629(92) 90723-4

Romagnoli, E., Minisola, G., Carnevale, V., Scillitani, A., Frusciante, V., Aliberti, G., and Minisola, S. (1998). Assessment of serum total and bone alkaline phosphatase measurement in clinical practice. Clinical Chemistry and Laboratory Medicine 36, 163-168. doi:10.1515/ CCLM.1998.030

Salo, L. A., Yliniemi, T., Larmas, M., and Nieminen, M. (1986). Phosphatase and peptidase activities in reindeer antler throughout the growth cycle. Journal of Interdisciplinary Cycle Research 17, 1-6.

Seijas, S. M. (2001). 'Censo Neotropical de Cisnes, Período 1998-2000.' (LOLA: Buenos Aires, Argentina.)

Seiser, P. E., Duffy, L. K., McGuires, A. D., Roby, D. D., Golet, G. H., and Litzow, M. A. (2000). Comparison of pigeon guillemot, Cepphus columba, blood parameters from oiled and unoiled areas of Alaska eight years after the Exxon Valdez oil spill. Marine Pollution Bulletin 40, 152-164. doi:10.1016/S0025-326X(99)00194-0
Silva-Garcia, C. M., and Brewer, G. L. (2007). Breeding behavior of the coscoroba swan (Coscoroba coscoroba) in El Yali wetland, central Chile. Ornitologia Neotropical 18, 573-585.

Solberg, H. E. (1987). International Federation of Clinical Chemistry (IFCC) Scientific Committee, Clinical Section. Expert Panel on Theory of Reference Values (EPTRV) and International Committee for Standardization in Haematology (ICSH) Standing Committee on Reference Values. Approved recommendation (1987) on the theory of reference values. Part 5. Statistical treatment of collected reference values. Determination of reference limits. Clinica Chimica Acta 170, S13-S32.

Takenaka, A., Gotoh, S., Watanabe, T., and Takenaka, O. (1988). Developmental changes of plasma alkaline phosphatase, calcium and inorganic phosphorus in relation to the growth of bones in the Japanese macaque (Macaca fuscata). Primates 29, 395-404. doi:10.1007/ BF02380962

Tilgar, V., Mänd, R., Ots, I., Mägi, M., Kilgas, P., and Reynolds, S. J. (2004a). Calcium availability affects bone growth in nestlings of free-living great tits (Parus major), as detected by plasma alkaline phosphatase. Journal of Zoology 263, 269-274. doi:10.1017/S0952836904005254

Tilgar, V., Ots, I., and Mänd, R. (2004b). Bone alkaline phosphatise as a sensitive indicator of skeletal development in birds: a study of great tit nestlings. Physiological and Biochemical Zoology 77, 530-535. doi:10.1086/420947

Tilgar, V., Kilgas, P., Viitak, A., and Reynolds, S. J. (2008a). The rate of bone mineralization in birds is directly related to alkaline phosphatase activity. Physiological and Biochemical Zoology 81, 106-111. doi:10.1086/523305

Tilgar, V., Kilgas, P., Mägi, M., and Mänd, R. (2008b). Age-related changes in the activity of bone alkaline phosphatase and its application as a marker of prefledging maturity of nestlings in wild passerines. The Auk 125, 456-460. doi:10.1525/auk.2008.07008

Villegas, A., Sanchez, J. M., Costillo, E., and Corbacho, C. (2002). Blood chemistry and haematocrit of the black vulture (Aegypius monachus). Comparative Biochemistry and Physiology. A. Comparative Physiology 132, 489-497.

Viñuela, J., and Ferrer, M. (1997). Regulation of growth in red kites and imperial eagles. The Wilson Bulletin 109, 92-101.

Viñuela, J., Ferrer, M., and Recio, F. (1991). Age-related variations in plasma levels of alkaline phosphatase, calcium and inorganic phosphorus in chicks of two species of raptors. Comparative Biochemistry and Physiology. A. Comparative Physiology 99, 49-54. doi:10.1016/03009629(91)90233-3

Warner, G. P., Hubbard, H. L., Lloyd, G. C., and Wuthier, R. E. (1983). Pi and Ca metabolism by matrix vesicles prepared from chicken epiphyseal cartilage microsomes by isosmotic Percoll density-gradient fractionation. Calcified Tissue International 35, 327-338. doi:10.1007/ BF02405054

Watkins, B. A., Li, Y., Allen, K. G. D., Hoffmann, W. E., and Seifert, M. F. (2000). Dietary ratio of (n-6)/(n-3) polyunsaturated fatty acids alters the fatty acid composition of bone compartments and biomarkers of bone formation in rats. Journal of Nutrition 130, 2274-2284.

Whitehead, P. J., and Tschirner, T. (1990). Magpie goose, Anseranas semipalmata, nesting on the Mary River floodplain, Northern Territory, Australia: extent and frequency of flooding losses. Australian Wildlife Research 17, 147-157. doi:10.1071/WR9900147

Manuscript received 19 November 2009, accepted 16 September 2010 